\title{
Orghe Kelantan: A Preliminary Study
}

\author{
Murina R. Pawanteh and James B. Kuake
}

\begin{abstract}
Minority sub-cultural groups often pride themselves with a unique identity. Membership to such groups usually requires persons to be born into that community, or sometimes, marrying into that community is acceptable reason for inclusion into the inner-circle. The Orghe Kelantan people are different. Membership is bound by a single presumptive criterion - being able to speak the unique dialect of Loghat Kelate. Orghe Kelantan however are even more accommodating to those born outside the state of Kelantan who are visiting, working or have recently moved into the state who are able to converse, or attempt to learn Loghat Kelate. Routine practices of the unique culture of Orghe Kelantan are also not limited to locals of Malay origin, but commonly practised by Chinese and Indians who are born and grew up in the state of Kelantan. This makes the culture of Orghe Kelantan uniquely different from that of most creole cultures where religion may be a binding factor. Therefore, while the Orghe Kelantan of Malay descend would be Muslims, religious norms of Taoism, Buddhism and Hinduism would comfortably find its place side-by-side as practised by ethnic Chinese and Indian Orghe Kelantan respectively. As a result, the cultural identity of the Orghe Kelantan people either living in the state of Kelantan, or have emigrated outside of their home state for socio-economic prospects, remain intact and distinct, as demonstrated by elated response when the latter meets another Orghe Kelantan (even not initially known to the former), often in the form of greeting and conversation in Loghat Kelate. Orghe Kelantan are proud to be identified first as Kelantanese, and next as Malaysians. Their strong sense of loyalty and provincialism (semangat kenegerian) would best describe people of this unique sub-culture, no matter where they may be residing at any given time.
\end{abstract}

Index Terms-Identity, inner-circle, local dialect, Kelantan

\section{INTRODUCTION}

The state of Kelantan is reputed to have a long standing history of having lived in harmony despite cultural differences and the people of Kelantan can be categorised as a collective society, where group interests takes precedence. According to Sathian and Yeok [1] these ethnic communities have long co-existed with minimal interference from the ruling Malay elite of Kelantan, lending an image of a state with a strong sense of cordiality among diverse ethnic group. Its population is composed of the Malays (95.7 percent), Chinese (3.4 percent) and Indians $(0.3 \%)$ [2]. Raybeck [3], observed that Kelantan as a state on the

east cost of the peninsula of Malaysia is generally acknowledged as the most conservative and traditional of

Manuscript received July 25, 2016; revised July 30, 2016.

Murina R. Pawanteh is with KDU University College, Malaysia (e-mail: pmurina@kdu.edu.my).

James B. Kuake is with Visiting Faculty, UTAR, Malaysia (e-mail: jameskuake@yahoo.com). the Malaysia's state. Kelantan has always been a stronghold of traditional Malay culture and many practices, such as the shadow play, love magic and kite flying, that have largely died out on the west coast are still common in Kelantan. [4]. Making this one of the main factor Kelantan people are able to assimilate and embrace this Malay culture to form a societal identity.

In a multi-ethnic society such as Kelantan, there are many challenges to the development and creation of a societal identity. People in this kind of society have differing cultural backgrounds which, collectively, may either interfere or reinforce each individual's self-belongingness to the formation of a societal identity.

According to Liu, Volcic and Gallois [5], when people say they belong to a specific group or category, their membership are the basis of their identities. The identities that mark the boundaries between self and others or those between in-groups and out-groups explain a great deal about why people think and behave as they do. When speaking of membership as a basis of identity, further discussion shall be required to look at how the elements of culture and communication have a great influence on this membership that will eventually lead to a state identity.

Drawing on the above statements, positive intercultural communication within an inter-ethnic society should foster a better understanding among these ethnic groups that will eventually lead to a common future that carries a common culture and communication pattern amongst people living in this context. This, in return will assist in the establishment of a "one identity" that is resilient enough to be recognized as a Kelantan State Identity.

This paper is to examine exactly how intercultural communication enables a multi-ethnic state of Kelantan to form its own state identity despite the similar and differing ways Kelantanese communicate between cultures.

\section{THEORATICAL FRAMEWORK}

This study factored the Communication Theory of Identity (CTI) and the concept of Cultural Identity (CI), as a support in discussing the research findings on how intercultural communication in a multi-ethnic state of Kelantan shall assist in the formation of a state identity, whereby the people of Kelantan shall proudly call themselves Orghe Kelantan.

CTI is built on the notion by Hecht [6] that identity is an element of a social phenomenon rather than a central element of human existence. Hecht compared this to the Western ideology of "self" as a single, unified identity, whereas this concept argues that humans are inherently social beings, whose lives revolve around communication, relationship and communities

CTI, according to Hecht and Choi [7] (cited in Hyunyi 
Cho), presents a more comprehensive or synthetic view of identity integrating community, communication, social relationships, and self-concepts, while "locating" identity in all these layers. Therefore, this theory is formed on the argument that communication assists in the development of identity. Hecht [8] (cited in Hyunyi Cho), went on to explain that the relationship between communication and identity is reciprocal. From this perspective, communication helps build, sustain, and modify one's identity. This statement is further endorsed in Mead's work when he described that the relationship between self-identity and social highlights is the central role that communication plays in identity formation [9].

CTI suggests that there are four layers of identitiespersonal, enacted, relational, and communal layers - that interact with and are influenced by each other. He strongly posits that the four layers of identity do not exist separately. They always are interconnected with each other, a quality that is labelled, "inter-penetration."'[10].

While CTI builds on the relationship of communication and identity, Cultural Identity (CI), refers to those social identities that are also based on communication and cultural membership; they are our identification with and perceived acceptance into a larger cultural group, into which we are socialized and with which we share a system of symbols, values, norms and traditions [11]. De Vos [12] posits that CI provides "a sense of common origins, as well as common beliefs and values, or common values" and "serves as the basis of "self-defining in-groups". According to Yinger [13] ethnic attachment is a "genuine culture" that forms the person's "basic identity" and offers "a sense of historical continuity, embeddedness and a larger existence in a collectivity of one's group."

Another view described CI based on the relationship between culture and ethnicity as a kind of temporal continuity or common tradition linking its members to a common future, which is fostered by the communal life patterns and practices associated with language, behaviour, norms, beliefs, myths and values, as well as the forms and practices of social institutions.

\section{RESEARCH QUESTIONS}

Drawing on the discussion above, this research shall investigate the relationship between communication and culture that plays a significant role in the formation of a Kelantan identity where the people of Kelantan shall call themselves Orghe Kelantan. To assist in this investigation, two research questions were advanced:

RQ1: What are the significant socially constructed cultural identities that define an Orghe Kelantan identity?

RQ2: How, if at all can the assimilation of culture of the different ethnic groups assist in the formation of this identity?

\section{RESEARCH OBJECTIVES}

The general objective of this study is to determine the inter-play between the elements of culture and communication patterns resulting in the formation of an
Orghe Kelantan identity.

RO1: To identify the dominant and "common ground" of a socially constructed identity that will lead to the formation of Orghe Kelantan identity.

RO2: To determine if each culture have the capabilities to adapt to one culture that is instrumental to the Kelantan identity formation.

\section{LITERATURE REVIEW}

For the purpose of this research the definition of communication shall be general and broad enough to include the various perspective of communication and also the use of communication in different context.

Woods[14] defined communication as "systemic process in which individual interact with and through symbols to create and interpret meaning". She went further to argue that this definition highlights that communication is a process, and always in motion. She posits that it's hard to tell when communication starts and stops, because what happened long before we talk with someone may influence our interaction, and what occurs in a particular encounter may have repercussions in the future.

Secondly, communication is also "systemic" and it uses "symbols". According to Woods [15], the former means that it involves a group of interrelated parts that affect one another and people interact differently depending on the context that they are involved in. The latter she argues are abstract, arbitrary, and ambiguous representation of things. Symbols include all language and many nonverbal behaviours as well as art and music.

Lastly, the definition focuses on "meaning", which, according to Woods [16], is the heart of communication. She went on to argue that meaning is not intrinsic to experience but instead we create it, typically in the process of communication.

However, Samovar, Porter, McDaniel and Roy [17], conceived communication as a linear process with each phase of the interaction progressing as one thing happens at a time. An awareness of the interacting components promotes understanding the way communication functions when people exchange ideas and feeling.

Communication and culture is intertwined. As Hall [18] argued that "culture is communication and communication is culture," Samovar, Porter, McDaniel and Roy [19], further speak on this notion when they write that they believe that you "learn" culture via communication and at the same time communication is a reflection of your culture. They strongly belief that you cannot improve your intercultural communication skills without having a clear understanding of this phenomenon called culture.

Culture has been defined in many ways from pattern of perceptions that influence communication to a site of contestation and conflict [20]. Liu, Volcic, and Gallois [21] defined culture on the notion that culture vary from across different fields and that culture is pervasive in human life and governs people's behaviour. Drawing on this consensus, they defined culture as the particular way of life of a group of people, comprising the deposit of knowledge, experience, beliefs, values, traditions, religion, and notion of time, roles, spatial relations, worldviews, material objects and 
geographical territory. They elaborated that culture emphasizes the pervasive nature of culture, it confirms that culture is the product of communication and that our attitudes toward work and age, ethical standards, clothing, artistic expressions, ritual and customs, belief and health, the concept of time, social and political institutions, religious practices and even our superstitions, are all reflection of culture. As Dodd [22] argued that "culture is like the luggage we carry', and when we open each pocket of our cultural suitcases, we explore an interrelated set of group identities, beliefs, values, activities, rules and customs, institutions and communication patterns arising from our daily needs."

Drawing on Dodds declaration that culture explores on interrelated identities, Liu, Volvic and Gallois [23], (pp.170, 2004), write that individuals who acquire an intercultural identity are willing to negotiate these differences. They went further to elaborate that these people are able to reach intercultural agreements, they want to integrate diverse cultural elements, achieve an identity extension and wish to go beyond an 'unexamined identity", which is a stage of acceptance of dominant norms, a lack of willingness to look into one's identity and reconstruct or negotiate it.

Samovar [24] et.al emphasized that identity is important to the study of intercultural communication. They posit that identity is a multifaceted, abstract that plays an important role in daily communicative interactions and especially in intercultural communication.

Intercultural communication as defined by Samovar, Porter, and McDaniel [25] occurs when a member of one culture produces a message for the consumption by a member of another culture. To be more precise, intercultural communication involves interaction between people whose cultural perceptions and symbols systems differ enough to influence the communication event.

Scollon and Scollon [26] refer to three distinct understandings of intercultural communication as 'crosscultural communication', 'intercultural communication' and 'inter-discourse communication', respectively. They argued that studies in cross-cultural communication start from an assumption of distinct cultural groups and investigates aspects of their communicative practices comparatively and studies in "intercultural communication" mostly also start form an assumption of cultural differences between distinct cultural groups but study their communicative practices in interaction with each other.

Kelantan makes a good case study for many reasons. [Sathian and Yeok [27], discusses the changing notion of the Chinese identity in Kelantan by taking into consideration the political changes. They observed that Chinese Kelantan also possess an additional cultural orientation that is closely affiliated to the state and people of Kelantan. This is further endorsed by Raybeck [28] when he observed that rural Chinese in Kelantan exhibit strongly Malay-oriented cultural patterns in a public context, but preserved Chinese culture in their homes. He believed that the contextual manipulation of ethnic identity is distinctive of Kelantan born Chinese who demonstrate not only a sense of belonging to their state of birth/residence, but also political loyalty toward the state.

\section{Methodology}

This study takes a qualitative perspective as it is designed to investigate the existing phenomenon of a possible formation of a state identity. An in-depth interview with Kelantan people who were born and lived in Kelantan, will look more closely into the existence of this phenomenon.

\section{FINDINGS AND DISCUSSION}

Nine respondents were interviewed using a same set of prepared questions and executed by a singular enumerator to ensure consistency in question form as well as recording of responses. Transcription of the interview notes was done by the same individual. The following are a lattice of the responses across all nine respondents.

When the people of Kelantan call themselves Orghe Kelantan, what they have in mind is an exclusive, almost tribal in nature, socio-geographic group. Members of this group would stand out from those originating from other Malaysian states and regions, by differences in usage of a unique Kelantanese dialect (a hybrid of the Malay language), hence taking a name popularly known as Loghat Kelate. Influence of Thai (due to geo-political proximity of the state of Kelantan with the south of Thailand), Arabic and Chinese (due to the historical presence and influence of traders from the latter two cultures) is present not only in the Loghat Kelate but also in the mannerism or budi Bahasa (courtesy code) of the Orghe Kelantan. The facial and physical attributes of Orghe Kelantan are frequently likened to fair and gentle maidens, and handsome men with laidback attitude (described in a positive way), attributes hardly disputed for generations among fellow Malaysian from across the country.

Orghe Kelantan are known for their fiercely loyal (take pride of their home state of Kelantan), close-knitted, cliquish and clannish behaviour (among fellow Orghe Kelantan), where upon discovering a stranger even during the very first meeting, they would immediately anoint each other as a non-biological kin (brother or sister).

Orghe Kelantan are devoted to their religion, be it Islam, Taoism, Buddhism or Hinduism as according to their respective ethnicity but a stronger loyalty or provincialism (semangat kenegeriaan) to their home domicile i.e. the state of Kelantan binds them as one Orghe Kito (inner circle). When travelling, working or studying outside of their home state of Kelantan Orghe Kelantan would warmly welcome fellow Kelantanese in the Loghat Kelate but without prejudice to Orghe Luar (those outside of) their inner-circle.

Orghe Kelantan of Malay descend are rather devout Muslims. There are common incidences where a prospective groom's religious devotion supersedes his material wealth, education level, social status and physical attractiveness, as in the eyes of the bride's parents. It is noted that Orghe Kelantan, while in majority are ethnic Malays, a small number of ethnic Chinese and Indian Orghe Kelantan exist (totalling under 10 per cent in the state of Kelantan). Orghe Kelantan identifies themselves as Kelantanese first, then only ethnically Malay, Chinese or Indian. Ultimately, Loghat Kelate binds them. Even Orghe Luar who work or live in the state of Kelantan for a short time but are able to 
converse in Loghat Kelate would be considered as inner circle. As agreed by many sociolinguists, language is the universal identifier. Even tourists who attempt to converse with locals in the local language or dialect, are welcomed warmly because of the former's effort to learn and try to 'assimilate'. Local traders may provide extra discount to such tourists as a reward for their effort.

It is also noted that Orghe Kelantan of non-Malay descend, while embracing Kelantanese way of life, i.e. language, food, dressing, hobbies; they are not to be confused with Peranakan (locally born) Chinese. The term Peranakan refers to a creole-type ethnic group as a result of inter-ethnic marriage between Chinese men with local women [29]-[30]. Ethnic Chinese Orghe Kelantan respondents to this research often likened themselves to the Peranakan of Malacca due to similar successful complete assimilation in their way of life to that of the local Malay majority ethnic hosts.

Perhaps this is because some Kelantanese Peranakan Chinese adopt Malay sounding names, in spite of the absence of inter-marriage in their ethnic lineage.

Both ethnic Malay minority together with non-Malay Orghe Kelantan also practise Malay cultural elements in daily life such as dressing (wearing batik sarong (unisex costume), semutar (headgear for men), kebaya (lacy blouse with sarong for women), cuisine (enjoying budu (fermented fish paste), nasi dagang and nasi kerabu (both rice entrees with herbs and fish meat), gulai (chilli paste), ikan singgang (fish soup)), in particular eating using their fingers instead of any cutlery, engage in Orghe Kelantan pastime (raising birds for bird-singing competition, dances and music such as makyong (a type of Thai influence dance), wayang kulit (shadow puppet) and dikir barat (singing recital), kite (wau bulan) flying) and speak Loghat Kelate. However, visitors including non-Orghe Kelantan, are welcomed into the homes of the Orghe Kelantan with utmost courtesy with the word selo (welcome).

Orghe Kelantan are largely matriarchal where the women-folk heads the family, are savvy in business and are extremely financially independent from their husband. Most Orghe Kelantan women wear their wealth on their wrists and upper arms in the form of (yellow) gold bracelets, bands and (stacks of) bangles, perhaps reflecting some historical Thai influence here.

These distinct socio-cultural traits of Orghe Kelantan remain distinct from other Malaysians and are passed down from one generation to the next, usually through word of mouth. The older generation would even craft stories for the young ones to more easily understand and remember, with much of these stories highlighting the way of life, traditional practices, and lifestyle of Orghe Kelantan of earlier generations.

Also, exposure to the Orghe Kelantan people, either via one parent of such descend, friends, neighbours or living amongst Orghe Kelantan, seem to exert a strong influence toward adoption of Orghe Kelantan ways by Orghe Luar. Meanwhile, Orghe Kelantan are always proud and gladly share their culture with all whom they meet or maintain prolonged contact with i.e. assimilate with all who come across and discover as well as appreciate the former's unique culture.

\section{SUMMARY OF FINDINGS}

Orghe Kelantan must be a person born and grow up in Kelantan, speak Kelantanese dialect (loghat) known as Loghat Kelate as their daily communication language.

Kelantanese ladies will wear batik sarung and the men will wear a headgear called semutar (a cloth that was wrapped around their head). Today, majority ladies in Kelantan especially among the older age group still wear batik sarung as their daily attire.

Another distinctive identity is that Orghe Kelantan eat budu with almost every meal (as a mandatory condiment) and is very proud of this unique food of theirs.

They have very strong sense of provincialism (semangat kenegerian) where they always regards their fellow Kelantanese as their own kind (inner-circle) or they address them as Orghe Kito. They feel very comfortable to be around their other fellow Kelantanese whenever they are out of their state and will form a very close relationship with other Kelantanese in the foreign land. They always refer non-Kelantanese from other states as Orghe Luar.

The capabilities to adapt to one culture, i.e. Malay culture, that is instrumental to the Kelantan identity formation.

\section{CONCLUSION}

Kelantan stands out as an intercultural communication entity that is dissimilar from other states in Malaysia because of the people's willingness to accept a common ground of attributes that is only exclusive and unique to the people of Kelantan. They are born and raised in Kelantan, acquire the fluency of the Loghat Kelate (dialect), retain their semangat (pride) of provincialism and willingness to adopt and preserve one culture that is central to their relationship as Orghe Kelantan, that is accepted through behaviours appropriate to the majority and simultaneously bridge any inter-ethnic differences. These elements will shape an in-group cohesion and create a sense of "togetherness" between people of Kelantan.

The ability of the Kelantanese people to exercise excellent intercultural communication has made it possible for the Kelantan people to form unique and exclusive identity that can ultimately be conceptualised as a Kelantan State Identity.

\section{REFERENCES}

[1] M. R. Sathian and M. N. Yeok, "Essentialising ethnic and state identities: Strategic adaptations of ethnic Chinese in Kelantan, Malaysia," Asian Studies Review. vol. 38, no. 3, p. 387, 2014.

[2] Department of Statistics, Malaysia. (2010). Population distribution and basic demographic characteristics. [Online]. Available: http://statistics.gov.my

[3] Raybeck, "Ethnicity and accomodation: Malay-Chinese relations in Kelantan, Malaysia," Ethnic Group, vol. 2, p. 242, 1980.

[4] Raybeck, "Ethnicity and Accomodation: Malay-Chinese relations in Kelantan, Malaysia," Ethnic Group, vol. 2, p. 246, 1980.

[5] L. Volcic and Gallois, Introducing Intercultural Communication: Global Cultures and Context, London: Sage, p. 163, 2011.

[6] M. L. Hecht, Encyclopedia of Communication Theory, Thousand Oaks, CA, U.S.: Sage, p. 139, 2009.

[7] M. L. Hecht and C. H. Cho, Health Communication Message Design: Theory and Practice, Thousand Oaks, CA, p. 139, 2011. 
[8] M. L. Hecht and H. Cho, Health Communication Message Design: Theory and Practice, Thousand Oaks, CA, U.S.:Sage, p. 139, 2011.

[9] M. O. Harris, Interracial Communication: Theory and Practice, Boston, MA, U.S.: Wadsworth, p. 73, 2001.

[10] M. L. Hecht and H. Cho, Health Communication Message Design: Theory and Practice, Thousand Oaks, CA, U.S.:Sage, pp. 140, 2011.

[11] L. V. Gallois, Introducing Intercultural Communication: Global Cultures and Context. London: Sage, pp.166 - 167, 2011.

[12] D. Vos and Y. K. Young, "Ideology, Identity, and Intercultural Communication: An analysis of differing academic conceptions of cultural identity," Journal of Intercultural Communication Research, vol. 36, no. 3, p. 240, 2007.

[13] Y. Y. K. Young, "Ideology, identity, and intercultural communication: An analysis of differing academic conceptions of cultural identity," Journal of Intercultural Communication Research, vol. 36, no. 3, pp. 240, 2007.

[14] J. Wood, Communication Theories in Action: An introduction, Boston, MA, U.S.: Wadsworth, p. 9, 2004.

[15] J. Wood, Communication Theories in Action: An introduction, Boston, MA, U.S.: Wadsworth, p. 10, 2004.

[16] J. Wood, Communication Theories in Action: An introduction, Boston, MA, U.S.: Wadsworth, p. 10, 2004.

[17] S. Porter, McDaniel and Roy, Communication between Cultures, $8^{\text {th }}$ ed. U.K.: Wadsworth, p. 8, 2013.

[18] Hall in Samovar, Porter, and McDaniel, Communication between Cultures, $8^{\text {th }}$ ed. U.K.: Wadsworth, p. 36, 2013.

[19] Samovar, Porter, and McDaniel, Communication between Cultures, $8^{\text {th }}$ ed. U.K.: Wadsworth, p. 36-37, 2013.

[20] M. Nakayama, Intercultural Communication in Contexts, $6^{\text {th }}$ ed. New York, NY, U.S.: McGraw-Hill, p. 88. 2013.

[21] L. V. Gallois, Introducing Intercultural Communication: Global Cultures and Context. London: Sage, p. 57, 2011.

[22] D. L. Volcic, Introducing Intercultural Communication: Global Cultures and Context. London: Sage, p. 57, 2011.

[23] Liu, Volcic, and Gallois, Introducing Intercultural Communication: Global Cultures and Context, London: Sage, pp. 170, 2011.

[24] Samovar, Porter, and McDaniel, Communication between Cultures, 8th ed. U.K.: Wadsworth, p. 213, 2013.

[25] Scollon and Scollon in Samovar, Porter, and McDaniel, Communication between Cultures, $8^{\text {th }}$ ed. U.K.: Wadsworth, p. 8, 2013.

[26] I. Piller, Intercultural Communication: A critical Introduction, Edinburgh, U.K.: Edinburgh University Press., p. 8, 2011.

[27] M. R. Sathian and M. N. \& Yeok,"Essentialising Ethnic and State Identities: Strategic Adaptations of Ethnic Chinese in Kelantan, Malaysia." Asian Studies Review, vol. 38, no. 3, p. 388, 2014.

[28] R. M. R. Sathian and M. N. Yeok, "Essentialising ethnic and state identities: Strategic adaptations of ethnic Chinese in Kelantan, Malaysia," Asian Studies Review, vol. 38, no. 3, p. 388, 2014.

[29] M. Y. Kee, Peranakan Chinese Porcelain: Vibrant festive ware of the Straits Chinese, Rutland, Vermont, U.S.: Periplus-Tuttle Publishing, pp. 21, 2009.

[30] J. B. Kuake, "Communicating the Baba-Nyonya cultural identity," Ph.D. dissertation, Department of Communication, Univ. Putra Malaysia, Serdang, Malaysia, 2010.

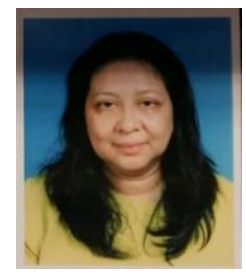

Murina R. Pawanteh is from the state of Terengganu, Malaysia. She earned a masters OF Arts degree in mass communication from the University of Leicester, United Kingdom in 1997. Her received her bachelor of science in library and information science is from the MARA University of Technology (UiTM), Shah Alam, Malaysia in 1988.

She is currently a senior lecturer at the School of Communication and Creative Arts, KDU University College in Shah Alam. Prior to joining KDU, she was a senior lecturer at HELP University, Kuala Lumpur, Malaysia. She was also consultant/trainer in the field of public relations. She has remarkable years lecturing in public and private universities which lead her to develop interest in research in the areas of communication.

Ms Pawanteh brings with her 23 years of work experience of which 15 years was in the corporate sector. Nothing goes to waste with Ms Pawanteh, she ensures that her work experience in the corporate sector is transferred to students through her lectures. Former students from all over the world still seek her advice on many things. Ms Pawanteh is always ready to assist her colleagues and students; she is very passionate about teaching and believes that you must be sincere when transferring knowledge to students. Her advice to students is always "Never be afraid to communicate, not all of us are born to be active communicators but with a little effort, we definitely can be one." Ms Pawanteh is current pursuing her PhD at Open University Malaysia (OUM). She is also a member of the Institute of Public Relations Malaysia (IPRM).

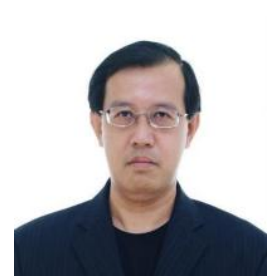

James B. Kuake earned a $\mathrm{PhD}$ in human communication from Universiti Putra Nalaysia in 2010. He received his masters of arts in communication was from The Ohio State University, Columbus, Ohio, USA in 1987, while his bachelor of arts in journalism was also from the same university in 1986.

$\mathrm{He}$ is currently adjunct faculty with Tunku Abdul Rahman University College, Kuala Lumpur, Malaysia and supervises undergraduate students' thesis project. He was previously dean at KDU University College, Petaling Jaya campus, Malaysia, Faculty of Communication. Prior to that he was Department of Communication Head at Sunway University Malaysia and earlier also helmed the at HELP University, Kuala Lumpur, Malaysia.

Dr Kuake's research interest is in micro-cultural issues involving minority communities in Asia; in particular identity issues amongst the Chinese. He is currently researching on the Chinese diaspora amongst minority creole cultural groups in Southeast Asia, particularly that of Generation Y. Born from mixed culture parentage himself, Dr Kuake is a creole of Chinese and Malay cultural origin, going back five generations from Melaka roots. 